\title{
DIAGNÓSTICO DA PRODUÇÃO DE HORTALIÇAS NA COMUNIDADE COLÔNIA NOVA, ABAETETUBA, PARÁ
}

\author{
Lu ciléia dos Santos ${ }^{1}$; Graciete Pereira Gomes²; Roberta Rowsy Amorim de Castro ${ }^{3}$; Ricardo \\ Eduardo de Freitas Maia 4 .
}

\author{
Universidade Federal do Pará (UFPA), Abaetetuba, Pará, Brasil, lucileiasantos46@gmail.com \\ UFPA, Abaetetuba, Pará, Brasil, ggracygomes@gmail.com \\ UFPA, Abaetetuba, Pará, Brasil, robertarowsy@ufpa.br \\ UFPA, Abaetetuba, Pará, Brasil, ricardomaia@ufpa.br
}

RESUMO: Este trabalho tem como objetivo produzir informações sobre o manejo em sistemas familiares de produção de hortaliças na Comunidade Colônia Nova, Abaetetuba, Pará. Foram entrevistadas, nos meses de abril a julho de 2017, 10 famílias que cultivam hortaliças atualmente na comunidade, com apoio do questionário semiestruturado com perguntas abertas e fechadas, numa perspectiva metodológica do Diagnóstico Rápido Participativo (DRP), que busca, além de colher dados dos participantes, que estes iniciem um processo de auto-reflexão sobre seu próprio contexto, seus problemas e formas de buscar soluções e melhorias, buscando a participação dos atores locais no levantamento de suas próprias demandas. Constatou-se que são cultivadas 15 espécies diferentes, que são utilizadas para consumo e/ou comercialização. Do ponto de vista da gestão da fertilidade do solo foi possível observar a predominância do uso de insumos orgânicos como esterco de galinha e farinha de osso. No que se refere ao controle de pragas e doenças há predominância de uso de produtos químicos, porém há iniciativas recentes que buscam controle alternativo. A comercialização é facilitada pela proximidade dos mercados consumidores, boas vias de acesso e condições de transporte, bem como as feiras da agricultura familiar presentes no território. A produção de hortaliças pode contribuir para ações de desenvolvimento da agricultura familiar no Baixo-Tocantins, sobretudo em condições de transição para uma agricultura sustentável que pode possibilitar melhorias na renda e democratização de alimentos saudáveis.

PALAVRAS-CHAVE: Adubação Orgânica, Agroecologia, Amazônia.

\section{DIAGNOSIS OF THE PRODUCTION OF VEGETABLES IN THE COLÔNIA NOVA COMMUNITY, ABAETETUBA, PARÁ}

ABSTRACT: The objective of this work is to produce information on the management of family systems for the production of vegetables in the Colônia Nova Community, Abaetetuba, Pará. From April to July 2017, 10 families who grew vegetables in the community were interviewed, with the support of the semi-structured questionnaire with open and closed questions, in a methodological perspective of the Participatory Rapid Diagnosis (PRD). To collect data from the participants, to initiate a process of self-reflection about their own context, their problems and ways of seeking solutions and improvements, seeking the 
participation of local actors in raising their own demands. It was verified that 15 different species are cultivated, that are used for consumption and / or commercialization. From the standpoint of soil fertility management, it was possible to observe the predominance of the use of organic inputs such as chicken manure and bone meal. With regard to pest and disease control, there is a predominance of chemical products, but there are recent initiatives of alternative control. Marketing is facilitated by the proximity of consumer markets, good access roads and transport conditions, as well as family farming fairs in the territory. The production of vegetables can contribute to the development of family farming in Baixo-Tocantins, especially in conditions of transition to a sustainable agriculture that can enable improvements in income and democratization of healthy foods.

KEYWORDS: Agroecology, Amazon, Organic fertilization.

\section{DIAGNÓSTICO DE LA PRODUCCIÓN DE HORTALIZAS EN LA COMUNIDAD COLONIA NOVA, ABAETETUBA, PARÁ}

RESUMEN: Este trabajo tiene como objetivo producir informaciones sobre el manejo en sistemas familiares de producción de hortalizas en la Comunidad Colonia Nova, Abaetetuba, Pará. Fueron entrevistadas, en los meses de abril a julio de 2017, 10 familias que cultivan hortalizas actualmente en la comunidad, el apoyo del cuestionario semiestructurado con preguntas abiertas y cerradas, en una perspectiva metodológica del Diagnóstico Rápido Participativo (DRP), que busca, además de recoger datos de los participantes, que éstos inicien un proceso de auto-reflexión sobre su propio contexto, sus problemas y formas de auto- buscar soluciones y mejoras, buscando la participación de los actores locales en el levantamiento de sus propias demandas. Se constató que se cultivan 15 especies diferentes, que se utilizan para el consumo y / o la comercialización. Desde el punto de vista de la gestión de la fertilidad del suelo fue posible observar la predominancia del uso de insumos orgánicos como estiércol de pollo y harina de hueso. En lo que se refiere al control de plagas y enfermedades hay predominio de uso de productos químicos, pero hay iniciativas recientes que buscan control alternativo. La comercialización se ve facilitada por la proximidad de los mercados consumidores, buenas vías de acceso y condiciones de transporte, así como las ferias de la agricultura familiar presentes en el territorio. La producción de hortalizas puede contribuir a acciones de desarrollo de la agricultura familiar en el Bajo-Tocantins, sobre todo en condiciones de transición hacia una agricultura sustentable que puede posibilitar mejoras en la renta y democratización de alimentos saludables.

PALABRAS CLAVE: Abono orgánico, Agroecología, Amazonia. 
A participação da agricultura tradicional familiar é expressiva no Território do Baixo Tocantins paraense ${ }^{1}$ e apresenta características como intensificação de mão de obra (BARROS, 2014), desenvolvida em pequenas e médias propriedades, e caracterizada pelo baixo uso de insumos externos, máquinas, equipamentos e tecnologias agrícolas (REIS, 2015). Contudo, essa agricultura vem passando por uma crise no sistema de pousio da capoeira, sobretudo, porque há uma diminuição significativa nas áreas (superfícies agrícolas utilizáveis - SAU) dos estabelecimentos rurais dos camponeses.

Conforme destacam Campos e Faria (2013) a shifting cultivation é uma técnica que há muito tempo é praticada pelos agricultores e camponeses da região amazônica. Tal técnica exige grande disponibilidade de áreas para pousios longos, onde na sequência é realizada a queimada da capoeira, sendo os resíduos provenientes da decomposição da

1 O Território Rural da Cidadania do Baixo Tocantins é bastante heterogêneo, englobando atividades de extrativismo vegetal, produção agrícola de culturas temporárias e perenes, produção pecuária, atividades pesqueiras, produção mineral, etc. que dão dinâmica as mesma, incorporados ao solo. Contudo, em virtude do aumento da pressão demográfica, as áreas disponíveis para implantação de cultivos agrícolas pelas famílias tornaram-se cada vez mais difíceis, o que influenciou na inviabilização dessa prática.

No Baixo Tocantins, região da pesquisa apresentada neste trabalho, a área média de estabelecimentos agrícolas no ano de 1996 era de apenas 16 hectares (CAMPOS; FARIA 2013), e é possível crer que, gradativamente, com base nesse dado, estas áreas, dedicadas a cultivos temporários, possam estar se reduzindo ainda mais, em decorrência da falta de alternativas técnicas à Shifting cultivation.

Martins et al. (2014) complementam, pois ao analisarem as atividades econômicas da agricultura familiar desse território, com ênfase nas áreas de terra firme, relatam que há limitações ligadas a problemas de fertilidade do solo, o que revela uma tendência ao investimento em culturas perenes, sobretudo em

atividades econômicas nos municípios que o formam, a destacar: Abaetetuba, Acará, Baião, Barcarena, Cametá, Igarapé-Miri, Limoeiro do Ajuru, Mocajuba, Moju, Oeiras do Pará e Tailândia (PLANO..., s/d) 
propriedades com menos de 50 hectares, que dinamizam os sistemas de produção por meio do uso de práticas agroecológicas disseminadas através das contribuiç̧̃̃es de Organizações Não Governamentais (ONGs). Assim, o monocultivo de espécies tais como maracujá, dendê e açaí vêm sendo uma das estratégias utilizadas pelos agricultores, porém já apresentam o entrave do surgimento de pragas e doenças (CAMPOS; FARIA 2013), além de problemas sociais e ambientais nos sistemas de produção das famílias.

O tamanho reduzido dos estabelecimentos agrícolas, a crise no sistema de pousio da capoeira, a facilidade de acesso aos mercados, como a feira da agricultura familiar, realizada a cada 15 dias no município de Abaetetuba, e outros espaços de comercialização, fazem com que produtores procurem estratégias de gestão de suas áreas ligadas à produção de hortaliças.

Resta saber em que medida esses sistemas de cultivo encontram sustentabilidade em longo prazo em função dos problemas ligados à gestão da fertilidade do meio, altos custos na aquisição de insumos industrializados e problemas ambientais pelo uso de tais produtos? Diante disso, esse trabalho teve como objetivo apresentar e discutir sobre o diagnóstico da produção de hortaliças na Comunidade Colônia Nova, localidade rural do município de Abaetetuba, estado do Pará, considerando que esta comunidade se enquadra dentro das características citadas anteriormente.

A pesquisa é fruto do projeto de extensão intitulado "Gestão da fertilidade dos solos e uso de insumos orgânicos em sistemas familiares de produção de hortaliças no munícipio de Abaetetuba, Pará", que visa contribuir para a gestão dos sistemas familiares de produção de hortaliças a partir do exercício, geração e validação de tecnologias na produção de hortaliças, que sejam ao mesmo tempo adaptadas à realidade local, acessíveis aos produtores, economicamente viáveis e menos agressivas ao meio ambiente, sendo a Comunidade de Colônia Nova em Abaetetuba, objeto de ação de pesquisa-extensão-intervenção, a partir da identificação de demandas locais, que serão conhecidas após a finalização da 
pesquisa e a análise dos dados coletados no diagnóstico.

A Colônia Nova está localizada entre os Km 04 e 16 da Rodovia Moura Carvalho PA-151 e se estende pelos ramais da direita e da esquerda da rodovia, a distância da sede do município de Abaetetuba é de 16 km. A formação da Comunidade teve início no ano de 1940 quando chegaram as primeiras famílias vindas da região nordeste do Brasil, em busca de novas oportunidades. Atualmente, residem na área aproximadamente 500 famílias que vivem de diversas atividades tais como: agricultura (plantio de mandioca e cultivo de hortaliças), empregos formais em empresas (Albrás, Alunorte, Hidro, etc), comerciantes, servidores públicos etc.

No cultivo de hortaliças trabalham cerca de 50 das famílias que produzem para o consumo e comercialização nas feiras do município de Abaetetuba, Moju e Barcarena, uma vez que há demanda por esses e o escoamento da produção é facilitado pelo asfaltamento das vias e proximidade com a sede dos municípios, principalmente o primeiro.
A pesquisa teve como base metodológica a participação dos agentes locais como atores do seu próprio desenvolvimento e a busca pelo diálogo de saberes, como impulsionadores de processos de desenvolvimento endógeno. Neste sentido, é necessário que os sujeitos envolvidos no processo estejam e busquem aproximar as ações no sentido de compreenderem a realidade e produzirem diagnósticos para, em seguida, formularem de maneira conjunta ações de experimentação de sistemas de produção tendo como base princípios menos agressivos ao meio ambiente.

Desta forma, foi utilizada a abordagem metodológica do Diagnóstico Rápido Participativo (DRP), que busca, além de colher dados dos participantes, que estes iniciem um processo de autoreflexão sobre seu próprio contexto, seus problemas e formas de buscar soluções e melhorias, buscando a participação dos atores locais no levantamento de suas próprias demandas. Assim O DRP tem como principal objetivo apoiar a autodeterminação dos atores enquanto coletividade/comunidade, fomentando 
um processo de Desenvolvimento Rural (VERDEJO, 2006). Ademais, o DRP tem como propósito a obtenção direta de informações primárias da comunidade como sua situação econômica e social, o estado dos recursos naturais disponíveis, levantamento e diagnósticos dos sistemas de produção, suas potencialidades e limitações, etc.

Neste sentido, foram entrevistadas, com apoio do questionário semiestruturado com perguntas abertas e fechadas, 10 famílias que atualmente cultivam hortaliças na Comunidade.

Com base nos dados coletados constatou-se que os produtores rurais da Comunidade Colônia Nova cultivam 15 espécies diferentes, sendo as mais comuns: coentro, caruru, alface, couve, chicória, cebolinha e jambu, que são cultivados por todos os entrevistados, conforme Quadro 1. Dois produtores estão inserindo duas novas hortaliças, a rúcula e o espinafre, pois segundo eles são culturas que podem se adaptar bem

2 As práticas "são atividades elementares realizadas dentro de uma ótica de produção, ou seja, as maneiras concretas de se fazer alguma coisa" (TESSIER, 1979 apud SILVA, 2011). "Trata-se ao clima e ao solo. A demanda dos mercados também é um fator que vem influenciando a adoção de novos cultivos nos sistemas de produção, pois segundo os olericultores consumidores, sobretudo da Vila dos Cabanos, distrito do município de Barcarena, buscam diversificar a alimentação através da aquisição dessas hortaliças. Alguns olericultores estudados já tentaram cultivar repolho e cenoura, mas não obtiveram sucesso em função de não adaptação das culturas ao tipo de solo, bem como pragas e doenças que inviabilizaram o plantio.

Para a prática ${ }^{2}$ do plantio as sementes são compradas em lojas agrícolas em Abaetetuba e Belém. Para espécies como couve, chicória, jambu e alface são feitas mudas em sementeiras que chegam a $10 \mathrm{~m} \times 1,20 \mathrm{~m}$ e depois transplantadas para os canteiros. É muito comum a aquisição de mudas de outros olericultores da própria comunidade. Já as outras espécies são plantadas diretamente nos canteiros definitivos.

das maneiras concretas de agir do agricultor e estão ligadas às condições das quais se exerce o ofício" (MILLEVILLE, 1987 apud SILVA, 2011). 
Quadro 1. Principais espécies, produção média mensal e finalidade das hortaliças cultivadas na Comunidade Colônia Nova, Abaetetuba, Pará.

\begin{tabular}{|c|c|c|c|}
\hline Espécie & $\begin{array}{l}\text { Produtividade } \\
\text { média (por mês) }\end{array}$ & $\begin{array}{l}\text { Produtores } \\
\text { que cultivam }\end{array}$ & Finalidade \\
\hline Alface (Lactuca sativa) & 312 maços & $100 \%$ & Consumo/Venda \\
\hline Caruru (Taninum paniculatum) & $22 \mathrm{~kg}$ & $100 \%$ & Consumo/Venda \\
\hline Cebolinha (A. schoenoprasum) & 62 maços & $100 \%$ & Consumo/venda \\
\hline Chicória (Cichorium intubys) & 547 maços & $100 \%$ & Consumo/Venda \\
\hline Coentro (Coriandrum sativum) & $848 \mathrm{~kg}$ & $100 \%$ & Consumo/Venda \\
\hline Couve (Brassica oleracea) & $22 \mathrm{~kg}$ & $100 \%$ & Consumo/Venda \\
\hline Jambu (Acmella oleracea) & 280 maços & $100 \%$ & Venda \\
\hline Feijão de Corda (Vigna unguiculata) & 10 maços & $32 \%$ & Consumo/Venda \\
\hline Mastruz (Dysphania ambrosioides) & 23 maços & $16 \%$ & Venda \\
\hline Hortelã (Mentha) & 3 maços & $16 \%$ & Venda \\
\hline Maxixe (Cucumis anguria) & $20 \mathrm{~kg}$ & $16 \%$ & Consumo/Venda \\
\hline Rúcula (Eruca sativa) & 10 maços & $16 \%$ & Venda \\
\hline Espinafre (Espinacea oleracea) & 30 maços & $16 \%$ & Venda \\
\hline Pimentinha (Capiscum spp) & $16 \mathrm{~kg}$ & $16 \%$ & Consumo/Venda \\
\hline Quiabo (Abelmoschos esculenta) & $7,5 \mathrm{~kg}$ & $16 \%$ & Venda \\
\hline
\end{tabular}

Fonte: Pesquisa de Campo (2017).

Os canteiros definitivos (Figura 1) têm tamanhos diferenciados e variam em média de $25 \mathrm{~m} \times 1,20 \mathrm{~m}$ até $50 \mathrm{~m} \times 1,20 \mathrm{~m}$. Antes do plantio é feita a limpeza do canteiro que é aberto para a incorporação dos adubos. Em seguida é feito o plantio das hortaliças, sempre observando a rotação de cultura. Há uma variação no período de adubação de acordo com cada tipo de hortaliça, a irrigação é feita com mangueiras cuja água utilizada provém de poço artesiano e poço comum. Apenas um produtor tem um sistema de irrigação desenvolvido com materiais recicláveis.

No período chuvoso (inverno amazônico) os canteiros são cobertos com filme agrícola (Figura 1) para que as chuvas não causem danos aos cultivos, já no verão são retiradas as lonas e em alguns canteiros são colocadas folhas de najá (Maximiliana maripa), para a proteção contra chuvas que ocorrem que mesmo ocorrendo em menor frequência 
nesse período podem causar danos

d'água que podem prejudicar alguns através do salpicamento, ou seja, a cultivos, como o coentro.

desagregação do canteiro pelos pingos

Figura 1. Canteiros de alface e coentro cobertos com filme agrícola.

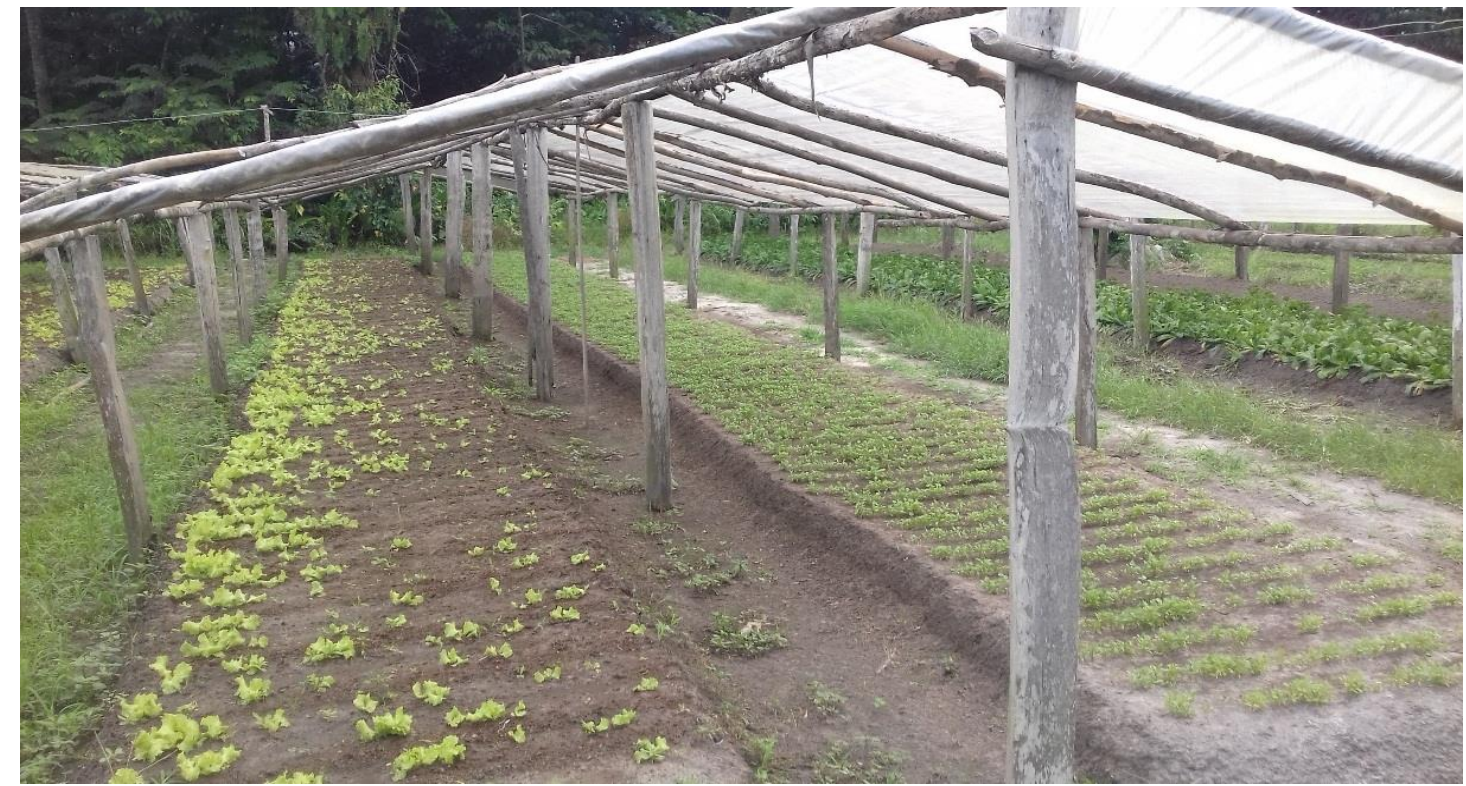

O solo na comunidade é de tipo predominante arenoso. Neste sentido, os agricultores tem utilizado a calagem, que é realizada no período que varia entre seis meses a um ano, para corrigir a acidez. Neste processo, após serem retiradas as hortaliças, o canteiro é limpo e é feita abertura de um sulco com a enxada. Neste é jogado o calcário, aproximadamente $2 \mathrm{~kg}$ de calcário no canteiro de 25mx1,20m, que é incorporado.
O uso de insumos orgânicos como esterco de galinha e farinha de osso são os meios mais comuns de gestão da fertilidade do solo. Petersen e Almeida (2008) assinalam que a fertilidade do solo está associada ao suprimento constante e equilibrado de nutrientes, considerando que esta não se centra somente na entrada e saída de nutrientes do sistema, mas valoriza a ciclagem permanente dos nutrientes por meio do manejo da biodiversidade funcional, pois a fertilidade abrange o solo e sua vegetação, onde 
ambos interagem dinamicamente entre si, realimentando ciclos de vida por meio de trocas de nutrientes e energia constantes.

As iniciativas locais de gestão da fertilidade do solo com uso de adubos orgânicos são eficientes e de acordo com Filgueira (2003) propiciam vários efeitos positivos ao solo, como: aumentar a retenção de água; melhora a porosidade, o arejamento e a estrutura, tanto em solos argilosos como em arenosos; amplia a vida microbiana, o que possibilita que fitopatógenos sejam eliminados; possibilita maior absorção de nutrientes pelo aumento da disponibilidade. A partir de suas pesquisas no estado do Pará, os autores Gusmão e Gusmão (2007) destacam que a adição de matéria orgânica melhora as dimensões biológicas, químicas e físicas do solo, sendo que sua adição é possibilitada por meio de compostos orgânicos. No Quadro 2 são disponibilizadas informações quantitativas sobre as estratégias do sistema de produção de olerícolas e métodos de gestão utilizados para cada espécie cultivada na Comunidade em estudo.

Quadro 2. Adubação, irrigação e colheita relacionadas ao cultivo de hortaliças, Comunidade Colônia Nova, Abaetetuba-PA.

\begin{tabular}{|l|c|c|c|}
\hline \multicolumn{1}{|c|}{ ESPÉCIE } & ADUBAÇÃO & IRRIGAÇÃO & COLHEITA \\
\hline Coentro & 2 vezes, no plantio e 20 dias depois & 2 vezes/dia & 30 a 45 dias \\
\hline Chicória & 2 vezes, no plantio e 15 dias depois & 2 vezes/dia & 30 dias \\
\hline Couve & 20 em 20 dias & 2 vezes/dia & 30 dias \\
\hline Cebolinha & 2 vezes, no plantio e 20 dias depois & 2 vezes/dia & 30 dias \\
\hline Jambu & 2 vezes, no plantio e 20 dias depois & 2 vezes/dia & 30 dias \\
\hline Mastruz & Duas vezes, no plantio e 20 a 25 dias depois & 2 vezes/dia & 30 a 45 dias \\
\hline Hortelã & Duas vezes, no plantio e 20 dias depois & 2 vezes/dia & 30 a 45 dias \\
\hline Alface & Duas vezes, no plantio e 20 dias depois & 2 vezes/dia & 30 a 45 dias \\
\hline Maxixe & Duas vezes, no plantio e 20 dias depois & 2 vezes/dia & 45 a 60 dias \\
\hline Feijão de Corda & Duas vezes, no plantio e 20 dias depois & 2 vezes/dia & 30 dias \\
\hline Rúcula & Duas vezes, no plantio e 15 dias depois & 2 vezes/dia & 30 dias \\
\hline Espinafre & Duas vezes, no plantio e 15 dias depois & 2 vezes/dia & 30 dias \\
\hline Pimentinha & Duas vezes, no plantio e 20 dias depois & 2 vezes/dia & 30 a 45 dias \\
\hline Caruru & Duas vezes, no plantio e 20 dias depois & 2 vezes/dia & 20 a 30 dias \\
\hline Quiabo & Duas vezes, no plantio e 20 dias depois & 2 vezes/dia & 45 a 60 dias \\
\hline
\end{tabular}

A colheita é feita de acordo com cada tipo de hortaliça, pois como vendem todos os dias da semana, há canteiros onde são feitas colheitas diárias para 
venda. Nesses, as espécies são colhidas a tarde e embaladas na manhã do dia seguinte, antes de irem ao seu destino final, o consumidor.

As pragas mais comuns encontradas no cultivo de hortaliças na comunidade são: paquinha, mosca branca, lagarta, formiga, lesma, mosquito, embuá e gafanhoto. Segundo os entrevistados, as paquinhas cortam as raízes à noite, as lesmas deixam uma gosma que fazem as folhas se deteriorarem rapidamente, e as lagartas e gafanhotos comem as folhas, deixando furos que tornam a hortaliça imprópria para o consumo (Figura 2).

Figura 2. Furos deixados pelas lagartas nas folhas de jambu.

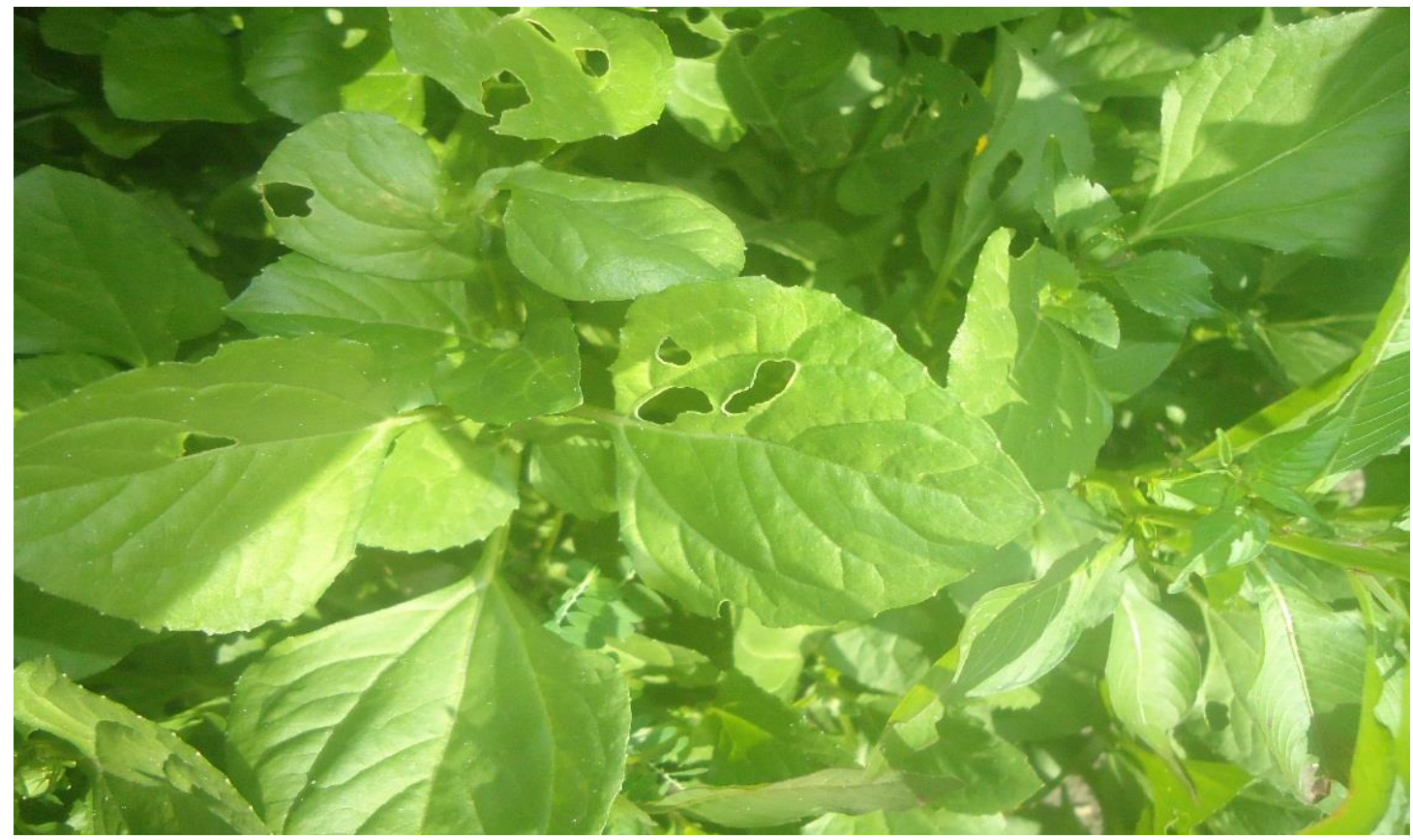

Os olericultores estão que resistem, como é o caso das lesmas, experimentando um produto caseiro, cuja eles utilizam outro produto mais eficaz mistura foi desenvolvida por eles, e como lesmicida. Há de se ressaltar que contém água sanitária+barrage+água, quando esses produtos são aplicados os que segundo eles vem trazendo resultado mesmos nem sempre fazem uso de contra essas pragas. Entretanto, para as 
máscara ou outro Equipamento de Proteção Individual (EPI).

Contudo, de acordo com os entrevistados, eles estão procurando alternativas para minimizar o uso de produtos químicos tóxicos. Para isso, buscam produtos orgânicos para o controle alternativo que melhore a condições dos alimentos e proporcione qualidade de vida para eles, que consomem, e para os consumidores para os quais comercializam. Exemplo disso é o de uma agricultora que planta uma espécie popularmente conhecida como catinga da mulata (Tanacetum vulgare L.) ao lado dos canteiros, estratégia utilizada em função do forte cheiro emitido pela planta, o que acaba servindo como repelente natural de insetos que podem prejudicar os cultivos.

Neste processo de modificações de práticas sócio produtivas existem dificuldades, conforme relatado pelos agricultores entrevistados. Porém, ressalta-se que é um processo mais complexo que a substituição de insumos químicos por orgânicos, conforme destacam Pacifico e Dal Soglio (2010) ao refletirem sobre o processo de transição agroecológica, sobre o qual constatam que:

$$
\begin{aligned}
& \text { Deve agir na perspectiva de } \\
& \text { interiorização de um novo } \\
& \text { procedimento do agricultor, um } \\
& \text { novo habitus produtivo, e deve } \\
& \text { considerar a complexidade das } \\
& \text { relações sociais e as especificidades } \\
& \text { das interações entre os grupos. A } \\
& \text { metodologia de transição, ao } \\
& \text { considerar o agroecossistema, deve } \\
& \text { considerar também que o manejo é } \\
& \text { realizado por um ator que toma } \\
& \text { decisões e é constituído por um } \\
& \text { social complexo e diverso } \\
& \text { (PACIFICO; DAL SOGLIO, 2010, p.62). }
\end{aligned}
$$

Os interlocutores elencam como dificuldades: a aquisição de crédito para o plantio de hortaliças; apoio técnico, uma vez que os órgãos públicos competentes como Empresa de Assistência Técnica e Extensão Rural do Estado do Pará (EMATER), Secretaria Municipal de Agricultura (SEMAGRI), Secretaria de Estado de Desenvolvimento Agropecuário e da Pesca (SEDAP) têm dificuldades em realizar assistência técnica, oficinas e dias de campo na comunidade; problemas fitossanitários; e a baixa remuneração (valor de comercialização) dos produtos. 
No contexto de adversidades, os olericultores da Comunidade Colônia Nova usam a estratégia da experimentação, pois ao plantar, adubar, produzir mudas e outros tratos culturais vão acumulando e trocando experiências entre si, semelhante à estratégia de trocas de experiências agroecológicas de agricultor para agricultor conhecida como "campesino-campesino" já desenvolvida em muitos países da América Latina (HOLT-GIMÉNEZ, 2008). Segundo este autor os intercâmbios de experiências entre agricultores permitem:

Alcanzar, adaptar, crear, usar y
defender el conocimiento
agroecológico en sus propios
términos es un ejercicio de
autonomía. Combinando teoría y
práctica, Campesino a Campesino
extrae el conocimiento de sus
fuentes campesinas así como de los
técnicos y de los científicos (HOLT-
GIMÉNEZ, 2008, p.109).

Dois exemplos de difusão tecnológica entre os agricultores da Comunidade em estudo que estão em processo de experimentação e inovação são: o uso de tijolos no entorno dos canteiros, que segundo os entrevistados possibilita economia de adubo, melhora o desenvolvimento das hortaliças e previne danos causados pela chuva; e o sistema de irrigação com uso de materiais alternativos (tampas de garrafas PET, canos PVC e palitos plásticos de pirulito) que facilitam o trabalho para realização da irrigação das culturas, considerando que na Comunidade a irrigação é feita com uso de mangueiras. As duas iniciativas podem ser vistas na Figura 3.

No que se refere à comercialização, dos produtores entrevistados, 60\% vendem direto para o consumidor e 40\% repassam os produtos para atravessadores. Os produtos são vendidos nas feiras de Abaetetuba, Vila dos Cabanos (município de Barcarena) e Moju. Há um produtor que distribui para supermercados da cidade de Abaetetuba. O escoamento da produção é feito pelos próprios agricultores através de transportes próprios e/ou coletivos, como ônibus e vans. 
Figura 3. Duas estratégias em experimentação pelas famílias olericultoras da Comunidade Colônia Nova, Abaetetuba, Pará.

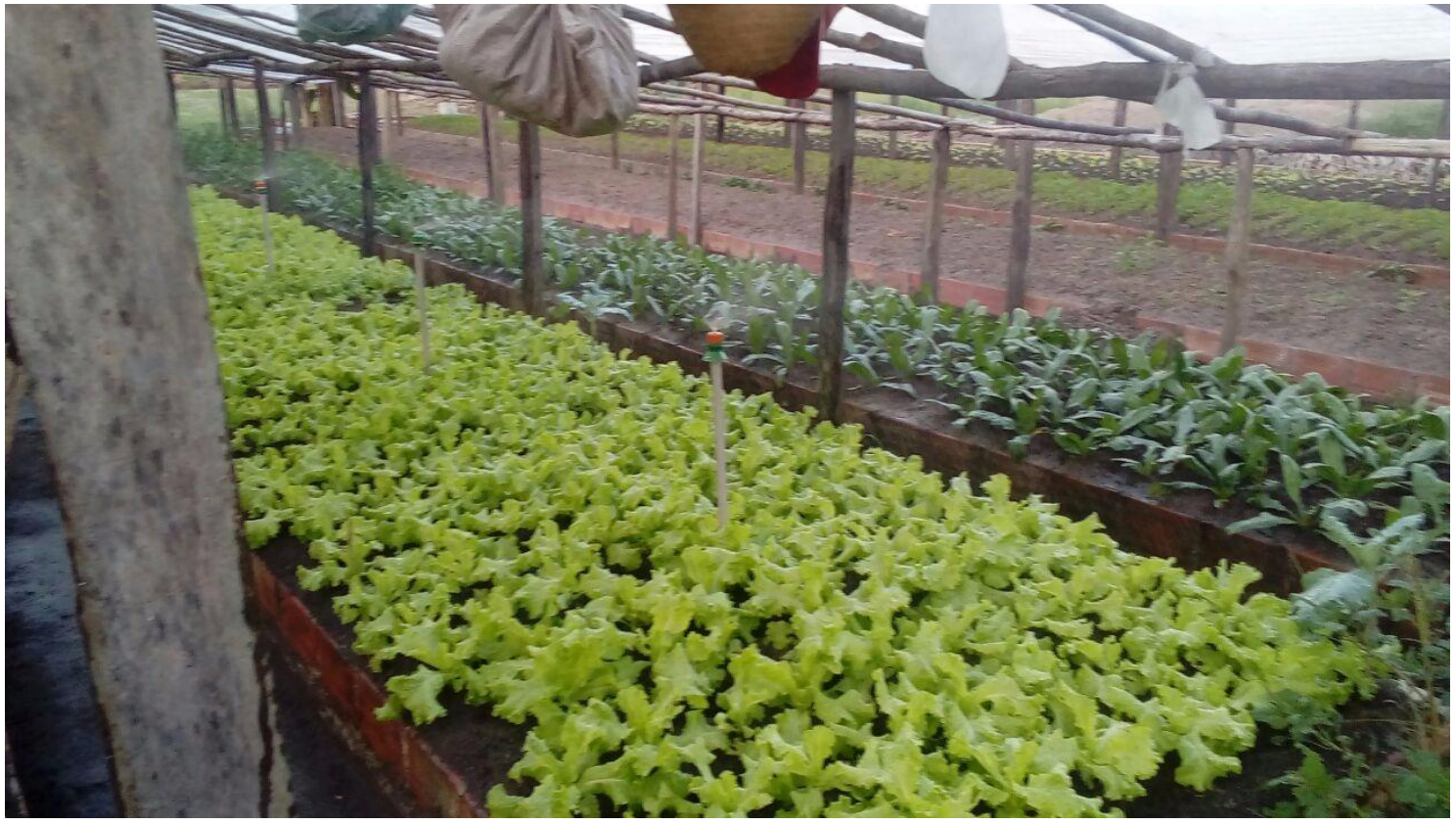

A comercialização das hortaliças compõe $100 \%$ da renda agrícola das famílias entrevistadas, a qual é complementada por rendas extras que provêm de atividades não agrícolas como empregos em empresas privadas, funcionalismo público e benefícios sociais, como por exemplo, aposentadorias, pensões e bolsa família.

As iniciativas locais de produzir alimentos saudáveis, sem o uso de agrotóxico, sinalizam um avanço interessante do ponto de vista de incremento de renda e valorização dos produtos, uma vez que a demanda por produtos saudáveis é crescente. Já no inicio do novo século Santos et al. (2001) notavam um crescimento do mercado de produtos orgânicos a 50\% ano no Brasil e no mundo. Por sua vez Chitarra (2005) constatou que o consumidor brasileiro está cada vez mais exigente em termos de alimentação saudável. Em que pese ainda se tratar de um nicho de mercado é importante ressaltar que há tendência de crescimento de demanda e o aumento de produção pode refletir numa democratização de alimentos menos nocivos à saúde e ao meio ambiente. No território do Baixo Tocantins há iniciativas de feiras da agricultura familiar que se 
configuram como espaços privilegiados para a comercialização desses produtos.

As condições para a resolução dos problemas podem ser melhoradas à medida que as organizações locais de representação dos agricultores sejam fortalecidas, uma vez que segundo os entrevistados, a associação local da Comunidade Colônia Nova pouco avança na demanda de políticas públicas. No mesmo sentido, os agricultores que relataram compor o quadro de sócios do Sindicato dos Trabalhadores e Trabalhadoras Rurais (STTR) dizem não participar ativamente ou veem o órgão de classe como possibilidade de acesso aos auxílios previdenciários e não como potencial possibilidade de organizar e ampliar o poder de barganhar políticas públicas para o setor junto aos órgãos da administração pública municipal, estadual e/ou federal.

Foi possível constatar através da pesquisa que na Comunidade Colônia Nova, nas estratégias de gestão da fertilidade, há predominância do uso de insumos orgânicos, como o esterco de galinha e farinha de osso. No que se refere ao controle de pragas e doenças há predominância de uso de produtos químicos, porém há iniciativas recentes que buscam o controle alternativo.

A comercialização é facilitada pela proximidade dos mercados consumidores, boas vias de acesso e condições de transporte, bem como as feiras da agricultura familiar presentes no Território. Portanto, os entraves que são relatados pelos agricultores em relação às atividades podem ser superados por meio da ampliação dos processos de gestão, inovação e organização promovidos pelos atores locais.

O estudo possibilitou ampliar a compreensão a respeito da produção e comercialização das hortaliças e pode contribuir para ações de desenvolvimento da agricultura familiar no Baixo-Tocantins, sobretudo em condições de transição para uma agricultura sustentável que pode possibilitar melhorias na renda e democratização de alimentos saudáveis.

\section{AGRADECIMENTOS}

A Universidade Federal do Pará - PróReitoria de Extensão (PROEX), que através do Programa Institucional de Bolsa de 
Extensão (PIBEX) apoia esta ação de pesquisa-extensão.

Aos agricultores que concordaram e participar e contribuíram com pesquisaextensão.

\section{REFERÊNCIAS}

BARROS, M. J. B. Políticas públicas de agricultura familiar no baixo Tocantins paraense, Boletim Amazônico de Geografia, n. 1, v. 1, 2014, p. 137-152.

CAMPOS, I.; FARIA, A. M. M. Crise e Reordenação Produtiva da Economia do Baixo Tocantins. Papers do NAEA (UFPA), v. 24, p. 1-22, 2013.

CHITARRA, M. I. F. Pós colheita de frutas e hortaliças: fisiologia e manuseio. $2^{a}$ ed. Lavras: UFLA, 2005.

FILGUEIRA, F. A. R. Novo manual de Olericultura: agrotecnologia moderna na produção e comercialização de hortaliças. $2^{a}$ edição. Viçosa: UFV, 2003.

GUSMÃO, S. A. L.; GUSMÃO, M. T. A. Produção de hortaliças com princípios orgânicos. Belém: UFRA, 2007.

HOLT-GIMÉNEZ,E. Campesino a Campesino: Voces de Latino América, movimiento campesino a campesino para La agricultura sustentable. Manágua, 2008. 294 p.

MARTINS, P. F. S.; PEREIRA, M. J. M.; MATOS, F. F.; SILVA JÚNIOR, B. R.; SCALABRIN, A. C. Limitações ao uso agropecuário das terras firmes na Amazônia e transformação dos sistemas de produção dos agricultores familiares no
Território do Baixo Tocantins. Revista Agricultura Familiar, n. 10, 2014, p. 67-85.

PACÍFICO, D.; DALSOGLIO, F. K. Transição para agricultura de base ecológica: um processo social. Revista Brasileira de Agroecologia, v. 5, p. 50-64, 2010.

PETERSEN, P.; ALMEIDA, E. Revendo o conceito de fertilidade: conversão ecológica do sistema de manejo dos solos na região do Contestado. Agriculturas, v. 5, n. 3, p. 16-23, set. 2008.

Plano Territorial de Desenvolvimento Rural Sustentável do Baixo Tocantins. (s/d). 83 p. Disponível em: <http://sit.mda.gov.br/download/ptdrs/pt drs_qua_territorio130.pdf>. Acesso em: 14 jul. 2017.

REIS, A. A. D. Desenvolvimento sustentável e uso dos recursos naturais em áreas de várzea do território do Baixo Tocantins da Amazônia paraense: limites, desafios e possibilidades. 2015. 271 f. Tese (Doutorado em Ciências do Desenvolvimento Socioambiental). Universidade Federal do Pará, Belém, 2015.

SANTOS, R. H. S.; SILVA, F.; CASALI, V. W. D.; CONDE, A. R. Efeito residual da adubação com composto orgânico sobre - crescimento e produção de alface. Pesquisa agropecuária brasileira, v. 36, n. 11, p. 1395-1398, 2001.

SILVA, L. M. S. A abordagem sistêmica na formação do agrônomo no século XXI. 1. ed. Curitiba - PR: APPRIS LTDA, 2011. v. 1. $157 p$.

VERDEJO M. E. Diagnóstico Rural Participativo: Um guia prático. Brasília: SAF/MDA, 62 p., 2006. 